\title{
RÉPLICA A «LOS PRESUPUESTOS ONTOLÓGICOS DEL DERECHO», DE DANIEL GONZÁLEZ LAGIER
}

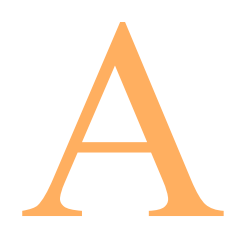

gradezco a Daniel González Lagier la atención que ha dedicado a mi artículo «La concepción estándar y la concepción realista del Derecho». Con ello cumple sobradamente la promesa a la que se refiere al inicio de su artículo, y muestra su seriedad en el ámbito no académico (en el ámbito académico, su tesis doctoral «Acción y norma en G.H.v. Wright» ya refleja sus cualidades).

Le agradezco también la cortesía que ha mostrado, al enviarme una copia de su artículo antes de su publicación.

Pero hasta aquí llega su amabilidad.

Daniel González Lagier discrepa de todas mis tesis. Está en su derecho. Sin embargo, su crítica no ha sido considerada. Pues Daniel González Lagier: a) deforma tantas ideas mías, y algunas de ellas las deforma tanto, que tengo que sospechar que le ha faltado buena intención o diligencia para entenderlas; b) mezcla temas y argumentos independientes, y los lanza todos revueltos contra mis tesis, como quien trata de golpear a ciegas a un adversario; y c) me abruma con informaciones elementales, que debería saber que ya tengo (pues algunas de ellas las tiene cualquier estudiante de Licenciatura), y que no he pasado por alto.

Nada más leer el artículo de Daniel González Lagier, le escribí contestando a sus observaciones. Pero dudé si escribir o no un artículo de réplica, para contestarle también públicamente.

Finalmente, han sido las incomprensiones citadas, incomprensiones que lecturas posteriores del artículo de Daniel González Lagier me han ido revelando, lo que me ha movido a escribir esta respuesta; pues deseo evitar que otros lectores del escrito de Daniel González Lagier se hagan una opinión equivocada acerca de mi pensamiento.

He procurado que mi respuesta a Daniel González Lagier sea respetuosa con él y con sus ideas: con él, porque le aprecio, y creo que él también a mí, a pesar del tono de su crítica; con sus ideas, porque, para rechazarlas, 
no es preciso ser irrespetuoso con ellas, deformándolas u ofreciendo una caricatura suya.

Sin embargo, aunque respetuosa, mi respuesta no va a ser indulgente con los errores cometidos por Daniel González Lagier.

El primero de ellos es haber titulado su artículo «Los presupuestos ontológicos del Derecho.». Pues nuestra polémica no versa sobre cuáles son las entidades presupuestas por las reglas jurídicas, o acerca de cuál es la doctrina ontológica presupuesta por el Derecho. Como se verá enseguida, nuestra polémica versa sobre la naturaleza del Derecho, o sobre qué concepción ontológica (acerca) del Derecho es la correcta.

1) He de empezar haciendo ciertas aclaraciones terminológicas.

Siempre he usado la expresión «hecho» en el sentido de «entidad factual». Por ejemplo, la p. 256 de mi libro Historia de la filosofía del Derecho contemporánea (que en adelante citaré como Historia...) comienza de la siguiente manera: «Olivecrona expresa así su factualismo jurídico, o sea, que el Derecho es un hecho, que todas o algunas entidades jurídicas son entidades factuales».

Y, para mí, una entidad factual, un hecho, siempre ha sido un objeto físico o un evento (véanse las pp. 28-29 de Historia...); pues parece que todo lo que existe en el mundo de los hechos, en el mundo espacio-temporal, es un objeto físico o un evento.

También en el artículo criticado por Daniel González Lagier uso la expresión «hecho» en el mismo sentido. Pero Daniel González Lagier, armado con el atomismo lógico de B. Russell, me objeta que «los objetos físicos no son hechos». Mas esto no es más que una terminología diferente: para B. Russell un hecho es, más o menos, un evento; por lo cual, dicha tesis viene a decir que los objetos físicos no son eventos.

Ésta es una tesis aceptable, pero discutible. Mas no la voy a discutir, dado que ni en el artículo criticado por Daniel González Lagier he sostenido la tesis contraria (la tesis de que los objetos físicos son eventos), ni es una tesis relevante para las cuestiones sobre las que versa el citado artículo.

En el presente escrito, mantendré la misma terminología: no porque me parezca preferible a la de B. Russell, sino porque usar ahora una terminología diferente a la usada en el artículo objeto de discusión (y en mis otros trabajos) enredaría las cosas.

2) Daniel González Lagier me atribuye la tesis de que «sólo existen los objetos físicos». Nunca he sostenido esta tesis; al contrario.

Por ejemplo, en Historia..., p. 32, hablo de «las entidades lingüísticas orales, las cuales no son objetos físicos, sino eventos». Y, en el artículo criticado por Daniel González Lagier, creo que el único pasaje que puede dar 
pie a atribuirme la tesis citada es uno en el que digo que el «texto legal es un hecho, un objeto físico» (p. 348). Pero este pasaje no significa «el texto legal es un hecho, o sea, un objeto físico»; significa «el texto legal es un hecho, concretamente, un objeto físico».

En la ontología que acepto tienen cabida tanto los objetos físicos como los eventos, al igual que en la ontología del atomismo lógico, aceptada por Daniel González Lagier (es más, puesto a decidir qué hechos son más básicos, si los objetos físicos o los eventos, me inclinaría, en principio, a favor de los eventos, por razones que expuse en el libro El Derecho como dogma, pp. 119-120; pero, como antes he dicho, voy a dejar a un lado estas cuestiones).

Es, pues, un error afirmar, como hace Daniel González Lagier, que «el problema básico de la concepción de Hernández Marín es haber adoptado un concepto homogéneo de «existencia», que toma como paradigma de existencia el modo de existencia de los objetos físicos».

3) Cualquier concepción que sostenga que las entidades, normas o reglas integrantes del Derecho son entidades factuales, hechos (bien objetos físicos, bien eventos), es una concepción factualista del Derecho (conforme a la definición de «factualismo jurídico» de Historia..., p. 58).

La concepción realista del Derecho es una concepción factualista del Derecho, por sostener que las reglas jurídicas son objetos físicos. Pero también la doctrina de Th. Geiger es una concepción factualista del Derecho; pues, según este autor, el Derecho está formado por regularidades de comportamiento social, por tanto, por eventos, no por objetos físicos (pp. 349-350 de mi artículo, y también Historia..., p. 293).

No entiendo, pues, por qué Daniel González Lagier me atribuye la tesis de que toda concepción factualista del Derecho concibe el Derecho como un objeto físico.

4) El idealismo jurídico es la doctrina que sostiene que el Derecho está formado por entidades ideales, por entidades que no son hechos (así defino el idealismo jurídico en Historia..., p. 57).

Por ello, al decir que la concepción estándar del Derecho es una doctrina jurídica idealista, lo que quiero decir es que dicha concepción sostiene que el Derecho está formado por entidades ideales. La concepción estándar del Derecho es idealista porque admite la existencia de entidades jurídicas ideales, o sea, de entidades jurídicas que no son hechos (ni objetos físicos, ni eventos).

También creía que ésta era una tesis clara de mi artículo; pero, al parecer, no lo es. Daniel González Lagier interpreta la tesis de que la concepción estándar del Derecho es una doctrina idealista de cuatro maneras distintas, ninguna de las cuales refleja mi pensamiento: 
Según la primera de sus interpretaciones, «la concepción estándar [del Derecho] es idealista porque admite la existencia de entidades que no son objetos físicos». No es esto lo que sostengo, pero se aproxima a lo que pienso: como acabo de decir, la concepción estándar del Derecho es idealista porque admite la existencia de entidades (jurídicas) que no son hechos (ni objetos físicos, ni eventos).

Sin embargo, las otras tres interpretaciones o formulaciones que Daniel González Lagier hace de mi tesis «La concepción estándar del Derecho es idealista» no se aproximan, ni remotamente, a mi pensamiento.

5) Para que una concepción idealista del Derecho, como la concepción estándar, fuera verdadera, sería necesario que fueran verdaderas las dos tesis siguientes: $1^{\mathrm{a}}$ ) Existe un mundo de entidades ideales, distinto al mundo de los hechos, y $2^{\mathrm{a}}$ ) las entidades (normas, reglas, principios, etc.) jurídicas pertenecen (todas o algunas de ellas) a este mundo ideal.

Conviene aclarar, antes de seguir adelante, que las cuestiones que estas tesis plantean no tienen nada que ver con el problema de los términos teóricos; ni este problema, a su vez, tiene nada que ver con la existencia de posibles teorías científicas irrefutables (como la teoría del homúnculo, a la que Daniel González Lagier alude en la nota 38 de su artículo, sin distinguir debidamente todas estas cuestiones).

6) Por lo que respecta a la existencia de un mundo distinto al mundo de los hechos, creo que todos tenemos la misma información al respecto, o sea, ninguna; todos sabemos lo mismo acerca de ese mundo ideal, pues ninguno sabemos nada.

Estando así las cosas, ¿qué es más racional?, ¿es más racional creer en la existencia de dicho mundo ideal o no creer en él?, ¿es más racional elaborar una teoría que presuponga o implique la existencia de ese mundo o elaborar una teoría que no tenga tal implicación?

Si la racionalidad es la racionalidad científica, creo que la respuesta es obvia: lo racional es no elaborar una teoría que presuponga la existencia de un mundo distinto al mundo de los hechos; lo racional es pensar que no existe un mundo de ideas (al menos, mientras no dispongamos de información adicional, que nos permita sospechar lo contrario).

Es cierto que la ontología actual admite la existencia de ciertas entidades ideales, como las entidades lógicas, las entidades matemáticas y las entidades semánticas (los sentidos de las expresiones). Pero éste es un tema polémico en la actualidad:

Por lo que respecta a las entidades semánticas, la tesis de que dichas entidades no existen «no es todavía un lugar común» (según palabras de S. Schiffer, en 1987), pero tiene cada vez más partidarios.

En cuanto a las entidades lógicas y matemáticas, muchos autores (como H. Putnam y W.V.O. Quine) admiten dichas entidades (las clases, especialmente) 
a regañadientes (porque no ven otra manera de dar cuenta del quehacer matemático); pero otros (como H. Field) rechazan esa ontología idealista y buscan explicaciones alternativas.

Lo que es indiscutible, en cualquier caso, es que, incluso aceptando la existencia de un mundo ideal, en dicho mundo, tal como lo concibe la ontología actual (esto es, como un mundo integrado a lo sumo por entidades lógicas, matemáticas y semánticas), no tienen cabida la mayoría de las entidades jurídicas ideales admitidas por la concepción estándar del Derecho: valores, principios, obligaciones, derechos subjetivos (derechos reales, derechos de crédito, derechos humanos, etc.), normas jurídicas consuetudinarias, etc. Ni siquiera las normas jurídicas legales de las que habla la concepción estándar del Derecho tienen cabida en el mundo de ideas de la ontología actual, dado que dichas normas legales son concebidas por la concepción estándar como cuasiproposiciones. ¿O acaso tememos que pensar que a los filósofos, a la hora de hacer inventario de lo que existe en ese mundo de ideas, se les ha pasado por alto que las entidades jurídicas también están allí, quizá escondidas en algún rincón?

Éste es el sentido de mí afirmación (p. 351 de mi artículo) de que ni siquiera las doctrinas ontológicas actuales más tolerantes aceptarían la ontología de la concepción estándar del Derecho. Dicha afirmación no tiene, pues, el sentido que Daniel González Lagier le atribuye, a saber: que la ontología actual rechaza la concepción estándar del Derecho porque aquélla (la ontología actual) sólo admite la existencia de objetos físicos (y, de nuevo, no entiendo cómo se le puede haber ocurrido a Daniel González Lagier esa interpretación de mi pensamiento; y si mi artículo le planteaba dudas respecto a qué es lo que sostengo en relación a la ontología actual, creo que las primeras páginas de la Historia... son meridianamente claras).

7) Siendo la actitud más racional creer que no existe un mundo distinto al mundo de los hechos y que, caso de que exista ese mundo, las entidades jurídicas no tienen allí cabida, es evidente cuál es la posición correcta respecto al problema de la naturaleza ontológica del Derecho: el Derecho es un hecho, como sostienen las concepciones factualistas o empiristas del Derecho.

Pero a Daniel González Lagier, como a la mayoría de los juristas, esta conclusión le parece «contraintuitiva», «chocante», «extraña», etc. Según él, el que una concepción del Derecho sea una concepción empírica del Derecho no es algo digno de elogio. Al parecer, es mucho más intuitivo, racional, plausible, elogiable, etc., sostener lo contrario, o sea, las dos tesis antes citadas: que existe un mundo de ideas y que allí moran las entidades jurídicas.

Mal está que se rechace la tesis de que el Derecho es un hecho. Pero que, a estas alturas de la evolución de la cultura humana, asentada en la ciencia y en la tecnología, se califique dicha tesis como chocante, extraña, etc., resulta 
increíble (una buena muestra de los residuos anticientíficos que todavía quedan en el pensamiento jurídico, por mucho que se admire de boquilla a Galileo). Es más: incluso en el caso de que la citada tesis fuera falsa, lo normal, lo racional, a la luz de nuestro conocimiento actual, es pensar que es verdadera.

8) A pesar de que el artículo de Daniel González Lagier comienza criticando la tesis de que el Derecho es un hecho, o sea, la concepción factualista del Derecho, posteriormente no pretende justificar la tesis contraria, o sea, la tesis de que el Derecho es idea.

Curiosamente, lo único que pretende a este respecto es mostrar que algunas de las entidades jurídicas ideales admitidas por la concepción estándar del Derecho, como los principios y el Derecho consuetudinario (las normas jurídicas consuetudinarias), son reducibles a hechos. Pues dice que «seguramente, las reglas consuetudinarias y los principios se pueden explicar a partir de hechos (no sólo objetos físicos) observables», y en sus conclusiones añade: «He tratado de mostrar que la noción de existencia no es homogénea y que, además de objetos físicos, admitimos la existencia de hechos, propiedades, etc. Esto abre la posibilidad de explicar los principios y las normas consuetudinarias como hechos».

No sé en qué parte de su artículo trata Daniel González Lagier de mostrar que existen propiedades o que admitimos su existencia. Pues las propiedades no son hechos, sino entidades ideales o abstractas; y en ningún momento trata Daniel González Lagier de probar que existen entidades ideales o abstractas. (Me parece que todo lo que ocurre es que Daniel González Lagier ha creído, erróneamente, que las propiedades son hechos, entidades factuales, no entidades abstractas).

$\mathrm{Al}$ margen de ello, si las normas jurídicas consuetudinarias y los principios jurídicos son (reducibles a) hechos, como sostiene Daniel González Lagier, ¿no implica ello que el Derecho es un hecho?; ¿cómo puede, entonces, parecerle extraña o contraintuitiva la tesis de que el Derecho es un hecho, o sea, la concepción factualista del Derecho? ¿O acaso lo que Daniel González Lagier quiere decir es que lo no reducible a hechos es precisamente la ley, pero sí lo son los otros elementos que, según la concepción estándar, forman parte del Derecho, o sea, los principios y el Derecho consuetudinario?

La verdad es justamente lo contrario: la ley es reducible a hechos; o más precisamente: la ley es un hecho. En cambio, los principios y las normas consuetudinarias ni son hechos, ni son reducibles a hechos; de la misma manera que el ángel de la guarda o la fuente de la eterna juventud no son hechos, ni reducibles a hechos. 
9) No obstante, Daniel González Lagier mantiene la tesis contraria, o sea, la tesis de que las normas jurídicas consuetudinarias y los principios son reducibles a hechos:

(A) Por lo que respecta a las primeras, la «reducción» sugerida por Daniel González Lagier de las normas jurídicas consuetudinarias o de las reglas sociales de H.L.A. Hart a hechos es justamente lo contrario de una reducción; es la duplicación (gratuita e innecesaria) de las entidades.

Pues si aceptáramos la «reducción» sugerida por Daniel González Lagier, junto a los hechos descritos en el definiens de la definición «reductora», tendríamos además una regla social o consuetudinaria (cuya naturaleza ontológica seguiría siendo dudosa), que ordena o prohíbe algo, y a la que alude el definiendum.

Dicho con un ejemplo, la citada «reducción» es como «reducir» la cólera de Júpiter a los truenos, mediante la siguiente definición «reductora»: «Júpiter está encolerizado si y sólo si truena».

(B) Por lo que respecta a los principios, ninguna de las cuestiones abordadas por Daniel González Lagier (cuál es el origen de los principios, cuáles son sus relaciones, inductivas o deductivas, con las normas, si los principios tienen carácter explícito o implícito, cuál es su contenido, etc.) responde debidamente, o sea, de forma clara y directa, a la cuestión de su naturaleza ontológica.

Sobre este punto, la única tesis directa, pero no clara, de Daniel González Lagier es que los principios son como la «ideología del ordenamiento jurídico». Con ello, sólo retrasamos el problema: ¿qué es la ideología del ordenamiento jurídico?; ¿cuál es la naturaleza ontológica de las entidades que la integran?; ¿son hechos (objetos físicos o eventos) o son ideas (como los números y las figuras geométricas)? Como ya he observado, Daniel González Lagier da por sentado que es posible explicar los principios como hechos o reducirlos a hechos. ¿Significa esto que la ideología del ordenamiento jurídico está formada por objetos físicos o eventos?

10) Una vez alcanzada la conclusión de que el Derecho, la ley, es un hecho, se plantea el problema de determinar cuáles son esos hechos con los que el Derecho se identifica. Para ello, es preciso tener en cuenta los usos lingüísticos, según los cuales, al Derecho pertenecen códigos, leyes, decretos, etc.

Según estos usos, propios de los juristas y de los no juristas, relativos a la palabra «Derecho» del Derecho español actual forma parte «algo» cuyo «contenido» es (literalmente) el siguiente: «El nacimiento determina la personalidad». Esto es lo que quería decir, al afirmar en mi artículo (pp. 348-349) que los usos lingüísticos relativos a la palabra «Derecho» establecen qué es lo que dicen literalmente los artículos de un código. 
Según Daniel González Lagier, dicha afirmación es un «error». No veo por qué. Además, y en contra de lo que sostiene Daniel González Lagier, lo que dicen literalmente los artículos de un código no depende «de los usos lingüísticos relativos a las palabras incluidas en tales textos».

Sin embargo, admito que en mi artículo no expresé la tesis expuesta con la debida claridad (aunque no sé si es esto lo que ha provocado, o lo único que ha provocado, la citada crítica de Daniel González Lagier).

11) Pero creo que tampoco Daniel González Lagier se ha esforzado en entender mi alusión al respecto de los usos lingüísticos.

Daniel González Lagier (véase la primera de sus conclusiones) parece sostener dos cosas: a) que si, para determinar cuál de las dos concepciones, la estándar o la realista, es la correcta decidimos atender a los usos lingüísticos relativos a la palabra «Derecho», los usos lingüísticos relevantes han de ser los de los juristas, no los de los no juristas; y b) que, de acuerdo con los usos lingüísticos de los juristas, la concepción correcta del Derecho es la concepción estándar, no la realista.

En cuanto al punto a), a los argumentos aducidos por Daniel González Lagier cabe oponer otros, al menos, del mismo peso: por ejemplo, que las reglas jurídicas son mensajes dirigidos directamente a los ciudadanos y que, por ello, éstos han de poder reconocer, al menos en gran medida, el Derecho, sin necesidad de recurrir a los juristas; y también que la cuestión polémica no puede ser decidida atendiendo, sin restricciones, a los usos lingüísticos de los juristas, porque estos usos ya incorporan normalmente una determinada concepción del Derecho (en la mayoría de los casos, la concepción estándar del Derecho); por lo cual, recurrir a dichos usos es decidir de antemano la cuestión.

Por ello, y por lo que respecta al punto b) anterior, Daniel González Lagier tiene razón. Pero sus tesis sólo significa lo que todos sabemos: que la concepción estándar es mayoritaria. Lo que muestra que no es ése el camino para decidir la cuestión polémica (si ése fuera el camino, la concepción estándar del Derecho sería la preferible, no sólo frente a la concepción realista que defiendo, sino frente a cualquier otra concepción del Derecho, sea o no realista, incluso frente a cualquier otra concepción idealista, diferente de la concepción estándar).

Para mí (voy a intentar exponer de nuevo mis ideas), el respeto a los usos lingüísticos es un factor a tener en cuenta a la hora de formular o enjuiciar una tesis (si no fuera así, con oportunas definiciones, nos veríamos obligados a aceptar que el Derecho moja y la lluvia quema). Pero no es ni el único, ni el principal factor a tener en cuenta; pues existen otros factores (por ejemplo, razones epistemológicas o de claridad expositiva) que pueden aconsejar y, por tanto, justificar una desviación de los usos lingüísticos dominantes. Pero una desviación grave e injustificada respecto a los usos lingüísticos 
puede ser suficiente para rechazar una tesis. Esto es lo que ocurre con la concepción de Th. Geiger, o incluso con una concepción realista con la de J. Frank, que identifica el Derecho con las decisiones judiciales.

La concepción realista que sostengo no se desvía de los usos lingüísticos de los no juristas relativos a la palabra «Derecho»; y esto es un mérito de dicha concepción, frente a otras concepciones factualistas, como la de Th. Geiger y J. Frank.

Pero tampoco se desvía de dichos usos la concepción estándar del Derecho. Por ello, este test de respeto a los usos lingüísticos de los no juristas, aunque sirve para descartar algunas doctrinas, como las concepciones factualistas citadas, no sirve para decidir entre la concepción realista que defiendo y la concepción estándar.

La concepción realista que defiendo se desvía, evidentemente, y también justificadamente, de los usos lingüísticos mayoritarios de los juristas, dado que éstos son partidarios de la concepción estándar; pues, si no lo hiciera, no habría ninguna diferencia entre ambas concepciones.

En cualquier caso, aún aceptando que la concepción realista se desvía de ciertos usos lingüísticos (sean los usos de los juristas, sean los usos de los no juristas), dicha desviación estaría justificada: los usos lingüísticos son respetables, pero más respetable es la verdad.

12) Una vez que hemos llegado al punto de que ese «algo» que forma parte del Derecho español actual, y cuyo «contenido» es (literalmente) «El nacimiento determina la personalidad», es un hecho, el «algo» en cuestión no puede ser otra cosa que una entidad lingüística escrita u oral.

Como sabemos, se trata de lo primero: las entidades lingüísticas que forman parte del Derecho actual son entidades escritas; son textos. Por ello, son objetos físicos (no eventos, como las entidades lingüísticas orales).

13) Es cierto, como observa Daniel González Lagier, que en mi artículo no preciso cuál es ese texto. Ello se debe a las dos razones siguientes:

(A) Por un lado, a que lo más importante es llegar a la conclusión de que el Derecho no puede ser otra cosa que un texto (al igual que los estatutos de una asociación o de una comunidad de propietarios, o el reglamento de la FIFA); pues esta conclusión es suficiente para abandonar la concepción estándar, en beneficio de la concepción realista.

La cuestión posterior de cuál es ese texto es, relativamente, una cuestión secundaria. $\mathrm{Y}$ es posible alcanzar aquella conclusión (la conclusión de que el Derecho es un texto), sin necesidad de abordar o resolver esta segunda cuestión (cuál es ese texto), como la presente exposición intenta poner en evidencia.

(B) Por otro lado, porque abordar y responder esta segunda cuestión exige otro artículo, distinto al que estaba escribiendo. En un libro titulado Teoría 
de la norma jurídica, que espero que será publicado en el año 1998, abordo este tema.

Mas en ningún caso (ni en el artículo, ni en el citado libro) mis referencias al texto de la ley «hacen pensar» que ese texto es una «abstracción», como dice Daniel González Lagier.

14) En mi artículo afirmo que la concepción realista del Derecho, al no admitir más entidades jurídicas (entidades pertenecientes al Derecho) que los textos legales, es más sólida que la concepción estándar del Derecho: ésta, junto a la existencia de textos legales, admite la existencia de muchas más cosas; y, como es evidente, cuantas más cosas presuponga una teoría, tanto más débil resulta, dado que el riesgo de equivocarse es mayor.

Daniel González Lagier critica la solidez de la concepción realista. Objeta que la solidez no es el único factor a tener en cuenta a la hora de juzgar una teoría. Es más, viene a decir, más importante que la solidez de una teoría es su potencia explicativa. Por ello, según Daniel González Lagier, no hay que aumentar la solidez de una teoría a costa de una disminución de su potencia explicativa.

Ésta es la objeción contenida en el pasaje de N. Rescher con la que encabeza su artículo, así como el relato de Galileo contenido en el texto.

A este respecto, no sólo estoy de acuerdo con Daniel González Lagier, sino que incluso en mi artículo (p. 351) se halla la misma objeción: «El único reproche que, desde el punto de vista teórico, cabría hacer a la concepción realista es el de que esta concepción del Derecho, por sólida que sea, admite tan pocas cosas que resulta insuficiente para explicar o comprender ciertos fenómenos, o para solucionar ciertos problemas».

Por esta razón, la crítica de Daniel González Lagier a la solidez de la concepción realista era innecesaria. La única crítica relevante al respecto contra la concepción realista consiste en hacerle el citado reproche: el reproche de que existen fenómenos que la concepción realista es incapaz de explicar y que, sin embargo, son explicables a partir de la concepción estándar del Derecho.

15) Este reproche, al que me acabo de referir, también aparece en el artículo de Daniel González Lagier. Es más, según las últimas palabra de su artículo, la tesis central de su crítica es precisamente ésa: que existen fenómenos que la concepción realista es incapaz de explicar y que, sin embargo, son explicables a partir de la concepción estándar del Derecho.

Dos son, si no me equivoco, los argumentos utilizados por Daniel González Lagier para defender su posición: por un lado, que la historia del pensamiento jurídico, desde la escuela de la exégesis hasta hoy, muestra la insuficiencia de la concepción realista (véase la última nota de su artículo); por otro lado, que un ejemplo de un fenómeno que la concepción estándar 
del Derecho es capaz de explicar, pero que es inexplicable para la concepción realista, es la actividad de los jueces (véase su sexta conclusión).

(A) En el último capítulo de Historia..., resumo lo que ha ocurrido en la historia de la filosofía jurídica durante los dos últimos siglos: una proliferación desmedida de (cuasi) entidades jurídicas, fruto de una incontenible verborrea. Pretender que ello ha estado motivado por necesidades teóricas y que, con semejante aparato conceptual, la teoría jurídica ha ganado en potencia explicativa, inalcanzable desde los supuestos del realismo jurídico, es ridículo.

(B) En cuanto a la actividad de los jueces, no es cierto que la concepción estándar explique dicha actividad y la concepción realista sea incapaz de explicarla. La verdad es justamente lo contrario:

Cuando la concepción estándar del Derecho explica dicha actividad aludiendo a principios jurídicos, valores, etc., proporciona una pseudoexplicación, dado que dichos principios, valores, etc., no existen. Y a quien afirme, como Daniel González Lagier, que tales principios, valores, etc., sí existen, le corresponde la carga de la prueba; una prueba que, naturalmente, ha de ser independiente del fenómeno que se intenta explicar.

Por contra, para la concepción realista, la actividad judicial es un fenómeno perfectamente explicable (precisamente, fue la actividad de los jueces lo que inspiró a algunos autores realistas su concepción del Derecho); pues, incluso cuando la actividad judicial alude a entidades inexistentes, el fenómeno encuentra su explicación en la conciencia, creencias, etc., de los jueces.

(C) Y, dado que la tesis central del artículo de Daniel González Lagier es precisamente la tesis que ahora estoy criticando, o sea, la tesis de que existen fenómenos que la concepción realista es incapaz de explicar y que, sin embargo, son explicables a partir de la concepción estándar del Derecho, finalizo esta crítica con un reto: le desafío a que indique un solo ejemplo de tales fenómenos (el de la actividad judicial, propuesto en su artículo, no sirve); y le doy un amplio plazo para ello: todo el tiempo que desee.

16) Una vez alcanzada la conclusión teórica de que no hay más Derecho que el de los textos legales (nos guste o no, no hay más cera que la que arde), es necesario abordar los problemas teóricos y prácticos que dicha conclusión plantea,

17) En el plano teórico, se plantean ciertos problemas como los señalados por Daniel González Lagier al comienzo de su artículo, en el pasaje que comienza de la siguiente manera: «¿Para qué queremos estudiar la derogación (que tantos quebraderos de cabeza puede proporcionar) si basta con quemar una norma para que ésta deje de existir?...».

Para responder a todos los problemas señalados (acertadamente) por Daniel González Lagier en este pasaje, sería necesario otro artículo, o varios artículos. A algunas de esas cuestiones (como la de la derogación) ya 
he respondido parcialmente ${ }^{1}$; y a otras estoy respondiendo en el libro que publicaré próximamente, y al que antes me he referido.

18) Por lo que respecta a los problemas de orden práctico que hay que afrontar desde la concepción realista que defiendo, dichos problemas tienen su origen, básicamente, en el hecho de que los textos legales (única realidad jurídica admitida por esa concepción realista) son frecuentemente imperfectos (como toda obra humana): son injustos, inadecuados, insuficientes, etc.

Daniel González Lagier se sorprende, como muchos juristas, de que se pueda calificar como justa o injusta una acción, una persona, una norma, etc., sin sostener, por ello, que existe algo así como el valor o la idea de justicia.

Ello revela el desconocimiento de una tesis fundamental: la tesis, en palabras de W. V. O. Quine ${ }^{2}$, de que el uso de un término general («blanco», por ejemplo) no nos obliga a aceptar en nuestra ontología la correspondiente entidad abstracta (la blancura, en este caso)

Si no fuera así, cada vez que alguien dijera, por ejemplo, (1) Este sombrero es blanco, estaría afirmando que existe la propiedad de la blancura (la entidad abstracta blancura, cual idea o forma platónica), y que (1) realiza una comparación entre dicha propiedad y el sombrero al que (1) se refiere.

Brevemente, sostener lo contrario a la tesis citada es hacernos a todos platónicos, en cuanto a la aceptación de universales.

Y si (1) no presupone, ni implica, que exista la idea de blancura, tampoco el enunciado «Esta norma positiva es (in)justa» implica o presupone que exista la idea de justicia.

O dicho de otro modo: sostener que existen cosas blancas y cosas no blancas no implica sostener la existencia de la idea de blancura; sostener que existen hombres sabios y hombres no sabios no implica sostener la existencia de la idea de sabiduría, etc. Del mismo modo, sostener que existen cosas justas y cosas injustas no implica sostener que existe la idea de justicia.

No hay ninguna diferencia, a este respecto, entre un término de valor y cualquier otro término general. Un término de valor (como «justo») sólo es un término general vago ${ }^{3}$ (más vago que, por ejemplo, el término general «blanco»).

${ }^{1}$ En Teoría general del Derecho y de la ciencia jurídica, Barcelona, PPU, 1989, 490 pp., p. 165-166, y en «Presente y futuro de la concepción jerárquica del Derecho», en Carlos Martín Vide (ed.): Lenguajes naturales y lenguajes formales, VII, Barcelona, PPU, 1992, pp. 19-30, pp. 24-25.

${ }^{2}$ QUINE, W. V. O.; «Identity, Ostension, and Hypostasis», en From a Logical Point of View, Cambridge, Massachusetts and London, England, Harvard University Press, 1980, pp. 65-79, p. 76 [«Identidad, ostensión e hipóstasis», en Desde un punto de vista lógico, traducción de Manuel Sacristán, Barcelona, Ariel, 1962, pp. 105-123, p. 119].

${ }^{3}$ Véase, en el mismo sentido, PRZELECKI, M.; «Truth-Value of Ethical Statements: Some Philosophical Implications of the Model -Theoretic Definition of Truth», en Peter Geach (ed.): Logic and Ethics, Dordrecht / Boston / Lancaster, Kluwer Academic Publishers, 1991, pp. 241-253, pp. 247 y ss. 
(19) La concepción estándar del Derecho aborda el citado problema de la imperfección de los textos legales, recurriendo a lo que denomino «reglas correctoras de la legalidad» (RCL) tradicionales, que aluden, entre otras cosas, a los principios generales del Derecho.

En el artículo criticado por Daniel González Lagier, analizo dichas reglas, una vez dejada a un lado la cuestión, ya discutida en las páginas anteriores, de si las entidades, como los principios generales del Derecho, a las que dichas reglas aluden, existen o no: «Muchas de estas RCL tradicionales, legales o no, plantean evidentemente el problema teórico de si existen o no esas fuentes de las que poder extraer las reglas supletorias de las reglas legales (si existen o no los principios generales del Derecho, el Derecho natural, los valores, etc.). Pero al margen de este problema teórico, del que ya hemos tratado en medida suficiente, las RCL plantean también un problema práctico, que es tan grave como el otro problema práctico, el de las leyes injustas o insuficientes, que esas mismas reglas pretenden resolver. Se trata de un problema de seguridad jurídica» (p. 356 de mi artículo).

A continuación expongo los problemas de seguridad jurídica que plantean las RCL tradicionales, suponiendo, por mor de la argumentación, que existen las entidades (Derecho natural, valores, principios generales del Derecho, etc.) que dichas reglas presuponen.

Pero, al parecer, esta suposición, sólo implícita en mi artículo, no la ha visto (o no la ha querido ver) Daniel González Lagier y me hace, por ello, las dos objeciones siguientes:

(A) $\mathrm{Si}$ los principios generales del Derecho no existen (como yo sostengo), el conjunto de los principios generales del Derecho no puede ser calificado como borroso, sino como vacío.

Así es, efectivamente. Pero si admitimos que existen, como yo admitía implícitamente en mi argumentación, el citado conjunto es borroso.

(B) La vaguedad de un término (la vaguedad del término "principios generales del Derecho») no implica que el término carezca de referencia (no implica que los principios generales del Derecho no existan). Me parece que es esto lo que Daniel González Lagier viene a decir en el pasaje que comienza con el ejemplo de los unicornios.

Pero ni yo, ni nadie (por cuanto sé) sostiene lo contrario, por la siguiente razón:

$\mathrm{El}$ enunciado «Todo término vago tiene referencia» (o « $\mathrm{Si}$ un término no tiene referencia entonces no es vago») es analítico (es una consecuencia de la definición de vaguedad). Por consiguiente, el enunciado «Todo término vago carece de referencia» es el enunciado contrario a un enunciado analítico. 
Por ello, el último enunciado citado (en conjunción al enunciado que afirma que existen términos vagos) implica una contradicción.

Tiene razón, pues, Daniel González Lagier, al oponerse al enunciado «Todo término vago carece de referencia» (al oponerse a una contradicción); pero el enemigo se lo ha inventado y era fácil de vencer.

Mis alusiones a la vaguedad de las RCL tradicionales, que aluden a los principios generales del Derecho, no iban dirigidas a negar la existencia de éstos. Al contrario, dichas alusiones suponen que dichos principios existen y tratan de poner de relieve los problemas de seguridad jurídica que aquellas reglas provocan. Éste era el enemigo a batir.

20) «Una concepción realista -escribe Daniel González Lagier- también debería ofrecer soluciones a los casos que prevén las RCL [tradicionales]».

$\mathrm{Mi}$ artículo contiene algunas sugerencias al respecto, que se resumen en lo que llamo «regla realista correctora de la legalidad» (RRCL). Se trata de una regla en la línea de la regla contenida en el art. 1, párrafo 2, del Código Civil suizo de 1907 (como es sabido, esta última establece que, en caso de laguna, el juez «decidirá según las reglas que él establecería si fuera legislador»); aunque hay muchas diferencias entre esta regla legal suiza y la RRCL.

Ciertamente, la RRCL, a semejanza de las RCL tradicionales, plantea problemas de seguridad jurídica, que mi artículo no oculta; al contrario. Pero, frente a las RCL tradicionales, la RRCL tiene claras ventajas, tanto de orden práctico, como de orden teórico:

En el plano de la práctica, la RRCL no abandona la seguridad jurídica en manos de cualquier juez, ni para cualquier supuesto, como ocurre en la actualidad. Por ello, y frente a lo que afirma Daniel González Lagier, la RRCL no es superflua, desde el punto de vista práctico.

Desde el punto de vista teórico, las ventajas de la RRCL sobre las tradicionales RCL son obvias, para un realista. Pero la RRCL también ofrece ventajas teóricas a un partidario de la concepción estándar como Daniel González Lagier. Pues le evita la ilusión de creer que las decisiones judiciales supuestamente basadas en principios jurídicos, valores, etc., son más controlables que las decisiones judiciales prudenciales. 